\title{
Effect of melatonin on maturation capacity and fertilization of Nili-Ravi buffalo (Bubalus bubalis) oocytes
}

\author{
G. Nagina ${ }^{1, *}$, A. Asima ${ }^{1}$, U. Nemat ${ }^{2}$ and A. Shamim ${ }^{1}$ \\ ${ }^{1}$ PMAS Arid Agriculture University, Rawalpindi, Pakistan \\ ${ }^{2}$ University of Animal and Veterinary Sciences Lahore, Pakistan
}

\begin{abstract}
This study evaluated the effect of melatonin supplementation of in vitro maturation media on in vitro maturation (IVM) and in vitro fertilization (IVF) rate of buffalo oocytes. Cumulus oocytes complexes (COCs) were aspirated from follicles of 2-8 $\mathrm{mm}$ diameter. In experiment I, COCs were matured in IVM medium supplemented with 0 (control), 250,500 , and $1000 \mu \mathrm{M}$ melatonin for $22-24$ hours in $\mathrm{CO}_{2}$ incubator at $38.5^{\circ} \mathrm{C}$ with $5 \% \mathrm{CO}_{2}$ and at $95 \%$ relative humidity. The maturation rate did not differ in media supplemented with melatonin at $250 \mu \mathrm{M}, 500 \mu \mathrm{M}, 1000 \mu \mathrm{M}$ and control $(0 \mu \mathrm{M})$. In experiment II, the matured oocytes were fertilized in $50 \mu 1$ droplets of Tyrode's Albumin Lactate Pyruvate (TALP) medium having $10 \mathrm{ug} / \mathrm{ml}$ heparin for sperm $(2 \mathrm{million} / \mathrm{ml})$ capacitation. The fertilization droplets were then kept for incubation at $5 \% \mathrm{CO}_{2}, 39^{\circ} \mathrm{C}$ and at $95 \%$ relative humidity for 18 hours. The fertilization rate was assessed by sperm penetration and pronuclear formation. Fertilization rate was improved when maturation medium was supplemented with $250 \mu \mathrm{M}$ melatonin compared to control. In conclusion, melatonin supplementation to serum free maturation media at $250 \mu \mathrm{M}$ improved the fertilization rate of buffalo oocytes.
\end{abstract}

Keywords: Buffalo, In vitro fertilization, In vitro maturation, Melatonin.

\section{Introduction}

Buffalo is important for ecologically disadvantaged agricultural systems as it not only provides meat, milk and working power but is also essential as a livestock source. Due to low maintenance requirements and good ability of feed conversion, buffaloes are considered ideal for low input systems and for the low cost production systems (Zicarelli, 1994). In spite of these qualities, the production potential of our dairy buffalo is low compared to dairy cattle in developed countries. Therefore consistent efforts are being made to improve the genetic potential of buffalo through assisted reproductive technologies. Artificial insemination that utilizes the superior male germplasm has been developed and is in use to some extent. Embryo transfer that utilizes superior male and female germplasm simultaneously is at the verge of experimentation in Pakistan. The efficiency of in vitro embryo production (IVEP) is lower in buffalo compared to cattle (Nandi et al., 2002). The low number of primordial and antral follicles as well as high incidence of follicular artresia is the major impediment for the in vitro embryo production in this species (Palta et al., 1998).

When cultured in vitro, oocytes are exposed to light, increased oxygen concentrations, increased or decreased concentrations of metabolites and substrates during handling of oocytes that causes oxidative stress (Agarwal et al., 2006). Naturally, free radicalscavenging antioxidants exist within the follicular and oviductal fluid that is able to protect the oocytes against oxidative stress (Wang et al., 2002), however, this system becomes insufficient under in vitro conditions. Melatonin and its metabolites have the ability to scavenge directly the free radicals and indirectly to act as powerful antioxidant (Adriaens et al., 2006; Kang et al., 2009). It has been reported that melatonin directly protects the oocytes of human and mouse from oxidative stress (Tamura et al., 2008). In bovine oocytes, melatonin stimulated the re-initiation of meiosis but it was unable to complete the meiosis or cleavage of oocytes after their maturation and fertilization in the laboratory (Sirotkin and Schaeffer, 1997). Present study was designed to assess the role of melatonin in in vitro maturation media on in vitro maturation (IVM) and in vitro fertilization (IVF) of buffalo oocytes.

Materials and Methods

This study was conducted at Physiology Laboratory, Faculty of Veterinary and Animal Sciences, Pir Mehr Ali Shah Arid Agriculture University, Rawalpindi.

\section{Reagents and chemicals}

The reagents and chemicals used in the study were purchased from Sigma (St. Louis MO, USA), or mentioned when purchased from other source.

\section{Collection of ovaries}

Nili-Ravi buffalo ovaries were collected immediately after slaughtering from local slaughterhouse at Sihala (Islamabad), and transported to laboratory within two hours in a thermos having sterilized saline solution held at $37{ }^{\circ} \mathrm{C}$ (Mehmood, 2007). In the laboratory, ovaries were washed with $70 \%$ ethanol for 30 seconds 
followed by three times rinse in saline solution (Jamil, 2007).

\section{Retrieval of oocytes}

A $10 \mathrm{ml}$ syringe attached to a needle (18 guage) was used to retrieve cumulus oocyte complexes from follicles having diameter of $2-8 \mathrm{~mm}$. The follicular fluid was collected in a conical tube and kept for 10-15 minutes. After discarding the supernatant, the sediment was collected in $60 \mathrm{~mm}$ petri dish and oocytes were searched under stereo microscope.

\section{Classification of oocytes}

The cumulus oocytes complexes were graded as: A Grade: having evenly granulated homogenous ooplasm with cumulus cells of three or more compact layers, B Grade: having homogenous ooplasm with two to three layers of cumulus cells, C Grade: having irregular ooplasm with less compact cumulus cells and D Grade: having irregular dark ooplasm and highly expanded cumulus cells (Singhal et al., 2009).

\section{Maturation of oocytes}

Total number of buffalo ovaries used in the present study was 1179 and the numbers of oocytes recovered were 1300 . Only grade A $(n=315)$ and $B(n=290)$ oocytes were used for INM. The oocytes were washed twice with oocytes wash media and once with IVM media ( $\mathrm{pH}$ 7.3-7.4). The oocytes were placed in IVM medium (Jamil et al., 2007) with some modifications (MM; TCM-199 supplemented with BSA $6 \mathrm{mg} / \mathrm{mL}, 10 \mathrm{IU} / \mathrm{mL} \mathrm{LH}, 0.5 \mathrm{ug} / \mathrm{mL} \mathrm{FSH}$, $1 \mathrm{ug} / \mathrm{mL}$ estradiol- $17 \beta$ and $50 \mathrm{ug} / \mathrm{mL}$ gentamicin) alone or with melatonin supplemented at $250 \mu \mathrm{M}, 500 \mu \mathrm{M}$ and $1000 \mu \mathrm{M}$ in four experimental groups covered with mineral oil. The maturation dishes containing oocytes were placed for 22-24 hours in an incubator with 5\% $\mathrm{CO}_{2}$, at $39{ }^{\circ} \mathrm{C}$ and at humidity of about $95 \%$.

\section{Sperm preparation}

Swim up technique was used to separate the most motile spermatozoa in medium known as Tyrode's albumin lactate pyruvate (Sperm TALP) (Jamil et al., 2007). Briefly, $3 \mathrm{~mL}$ of TALP medium (pH 7.3-7.4) was taken in each of the four $15 \mathrm{ml}$ tubes and incubated for two hours in an incubator at $39^{\circ} \mathrm{C}$ temperature and $5 \% \mathrm{CO}_{2}$. Cryopreserved buffalo semen was thawed at $37^{\circ} \mathrm{C}$ for 30 seconds. About $70 \mu 1$ of thawed semen was transferred into four $15 \mathrm{ml}$ tubes containing sperm TALP, placed at an angle of $45^{\circ}$ and incubated at $39^{\circ} \mathrm{C}, 5 \% \mathrm{CO}_{2}$ and $95 \%$ humidity. The supernatant containing the most motile spermatozoa was transferred to a $15 \mathrm{ml}$ falcon tube for centrifugation at $1600 \mathrm{rpm}$ for 10 minutes. The sperm pellet was suspended in fertilization TALP having $10 \mu \mathrm{g} / \mathrm{mL}$ heparin for capacitation. Neubauer hemocytometer was used for measuring sperm concentration (Hafez and Hafez, 2000) and sperm concentration was adjusted to $1 \times 10^{6} / \mathrm{mL}$ by adding fertilization media.

\section{In vitro fertilization}

Following maturation, oocytes were washed three times in the fertilization TALP and then 5-10 oocytes were incubated in $50 \mu \mathrm{l}$ droplets of fertilization TALP (mTALP) having sperm under mineral oil at $5 \% \mathrm{CO}_{2}$, $95 \%$ humidity and $39^{\circ} \mathrm{C}$ for 18 hours.

\section{Evaluation of in vitro maturation}

\section{Cumulus cell expansion}

After 24 hour of incubation, the degree of cumulus expansion was assessed using stereo microscope as; not expanded oocytes without loosened, partially expanded with slightly loosened or fully expanded oocytes with cumulus cells completely loosened.

Stage of nuclear maturation

After IVM, oocytes were vortexed in $1 \mathrm{ml} \mathrm{M}-199$ containing $300 \mu \mathrm{l} / \mathrm{mL}$ hyaluronidase for 2 minutes to completely denude the oocytes. The denuded oocytes were washed with simple maturation media, placed on grease-free slide and cover slipped with 4 droplets of Vaseline/Paraffin (40:1) mixture. Oocytes were slightly compressed and fixative (acetic acid and ethanol in the ratio of $1: 3 \mathrm{v} / \mathrm{v}$ ) was used for fixing oocytes for 5 minutes. Acetoorcein stain $(1 \%$ orcein in $45 \%$ acetic acid) was used for staining of oocytes. After 3-5 minutes, excess stain was removed from oocytes by a de-staining solution composed of acetic acid: distilled water: glycerol (1:3:1) in the same manner as staining of oocytes. Phase contrast microscope (400X) was used to determine the stage of maturation (Hewitt et al., 1998). Oocytes were classified at germinal vesicle (GV; prophase I having a prominent nucleolus), germinal vesicle breakdown (GVBD; condensation of chromosomes by resolution of nuclear membrane), metaphase I (M-I; arrangement of chromosomes at equator but without a polar body) and metaphase II (M-II; when polar body was extruded).

Assessment of in vitro fertilization

After $18 \mathrm{~h}$ of insemination, oocytes were stained as described earlier. Oocytes with penetrating head, with male pronucleus (MPN) and female pro-nucleus (FPN) were considered as normal fertilized. Oocytes with three or more pro-nuclei were considered as polyspermic.

\section{Statistical analysis}

The data on maturation rate of oocytes and IVF rate of in vitro matured oocytes were analyzed by chi square analysis. Statistically significant confidence interval was taken as $\mathrm{P}<0.05$.

\section{Results}

\section{Recovery of oocytes}

Oocytes were classified into four different grades on the basis of homogenous ooplasm and the compactness of the cumulus cells as shown in the Fig. 1. Data on the recovery of different grade oocytes from the ovaries is given in the Table 1. Total oocytes recovered from buffalo ovaries $(n=1179)$ were 1300 in number which were retrieved from follicles of 2-8 $\mathrm{mm}$ by aspiration method. Out of these oocytes grade $\mathrm{C}$ oocytes were higher $(28.07 \%)$ followed by grade D $(25.38 \%)$, grade A $(24.23 \%)$ and grade B $(22.30 \%)$. 


\section{Oocytes maturation in IVM media supplemented with melatonin}

Expansion of Cumulus Cells

The data on degree of cumulus expansion of buffalo oocytes with the supplementation of melatonin in IVM media are given in the Table 2 and Fig. 2 as well. Fully expanded oocytes were $33.04,42.85,38.88$ and $32.50 \%$ in control, $250 \mu \mathrm{M}, 500 \mu \mathrm{M}$, and $1000 \mu \mathrm{M}$ melatonin supplemented maturation media, respectively.

Degree of maturation of oocytes

The data on the number of oocytes at different stages of maturation after 24 hours of incubation are given in the Table 3 and Fig. 3. The oocytes that remained at GV stage were $5.12 \%$ and $3.03 \%$ in control and $500 \mu \mathrm{M}$ melatonin supplemented media. While no oocyte was found at GV stage in the media supplemented with $250 \mu \mathrm{M}$ and $1000 \mu \mathrm{M}$ of melatonin. The oocytes reaching GVBD were $12.82 \%$ in control, while $6.06 \%$, $9.09 \%$ and $6.25 \%$ in media supplemented with $250 \mu \mathrm{M}$, $500 \mu \mathrm{M}$ and $1000 \mu \mathrm{M}$ melatonin. The oocytes at M-I stage were $30.76 \%, 24.24 \%, 24.24 \%$ and $28.12 \%$ in control, $250 \mu \mathrm{M}, 500 \mu \mathrm{M}$ and $1000 \mu \mathrm{M}$ melatonin supplemented media, respectively. The MII stage oocytes were recorded as, $51.28 \% 69.69 \%, 63.63 \%$ and $65.62 \%$ in control, $250 \mu \mathrm{M}, 500 \mu \mathrm{M}$ and $1000 \mu \mathrm{M}$ melatonin supplemented media, respectively. Oocytes

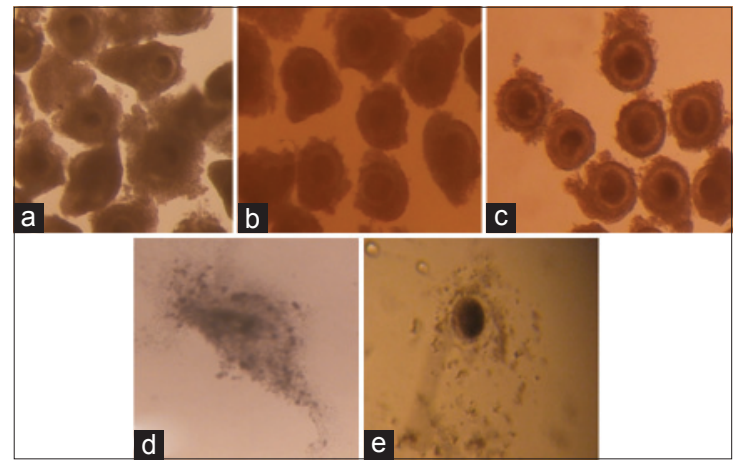

Fig. 1. Recovery of different grades oocytes from buffalo ovaries by aspiration. (a) Grade A oocyte with cumulus cells of 3-4 layers. (b) Grade B oocyte with cumulus cells of 2-3 layers. (c) Grade C oocytes cumulus cells maximum 1 layer. (d) Grade D oocyte highly denuded (e) or denuded (f). (400x by stereo microscope).

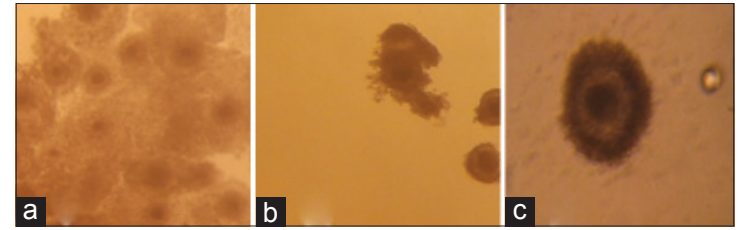

Fig. 2. Degree of expansion of oocytes complexes after 24 hours of IVM. (a) Fully expanded cumulus layer. (b) Partially expanded cumulus layer. (c) Not expanded cumulus layer. (400x by stereo microscope). at M-II were considered to be matured, the percentage of which in the media supplemented with different concentrations of melatonin was found slightly higher compared to control, however the difference remained non-significant $(\mathrm{P}>0.05)$.

Fertilization of oocytes (IVF)

The data on the effect of IVM media supplemented with different concentrations of melatonin on fertilization of buffalo oocytes after 18 hours of insemination are given in the Table 4 and Fig. 4 . The oocytes that were penetrated remained $2.3 \%$ in control and $10.25 \%$ when the oocytes were matured in $1000 \mu \mathrm{M}$ melatonin supplemented IVM media. Oocytes with 2PN were recorded as $25.58 \%, 46.15 \%, 43.58 \%$, and $23.07 \%$ in control, $250 \mu \mathrm{M}, 500 \mu \mathrm{M}$ and $1000 \mu \mathrm{M}$ melatonin supplemented groups. A small number of polyspermic oocytes $(10.25 \%)$ were found when the oocytes were matured in media supplemented with $1000 \mu \mathrm{M}$ melatonin. The number of oocytes that remained unidentified was $2.3 \%, 10.25 \%, 15.4 \%$ and $15.38 \%$, in control, $500 \mu \mathrm{M}, 250 \mu \mathrm{M}$ and $1000 \mu \mathrm{M}$ melatonin supplemented media.

Table 1. Frequency distribution of different grades of Oocytes recovered from buffalo ovaries $(n=1179)$ by aspiration method.

\begin{tabular}{lcc}
\hline Oocytes & \multicolumn{2}{c}{ Recovery rate } \\
\cline { 2 - 3 } & Total & Per ovary (\%) \\
\hline Oocytes recovered & 1300 & 1.1 \\
Usable oocytes (A, B) & 605 & 0.51 \\
Grade A (\%) & $315(24.2)$ & 0.26 \\
Grade B (\%) & $290(22.3)$ & 0.25 \\
Grade C (\%) & $365(28.1)$ & 0.31 \\
Grade D (\%) & $330(25.4)$ & 0.28 \\
\hline
\end{tabular}

Table 2. Effect of supplementation of melatonin in media for IVM on degree of cumulus expansion of buffalo oocytes after 24 hours of maturation.

\begin{tabular}{lcccc}
\hline IVM Media & $\begin{array}{c}\text { No. of } \\
\text { oocytes }\end{array}$ & \multicolumn{3}{c}{$\begin{array}{c}\text { Degree of cumulus expansion } \\
n(\%)\end{array}$} \\
\cline { 3 - 5 } & & $\begin{array}{c}\text { Not } \\
\text { expanded }\end{array}$ & $\begin{array}{c}\text { Partially } \\
\text { expanded }\end{array}$ & $\begin{array}{c}\text { Fully } \\
\text { expanded }\end{array}$ \\
\hline $\begin{array}{l}\text { Maturation } \\
\text { media }(\mathrm{MM})\end{array}$ & 115 & $34(29.6)$ & $43(37.4)$ & $38(33.0)$ \\
$\begin{array}{l}\text { Mm+250 } \mu \mathrm{M} \\
\text { melatonin }\end{array}$ & 112 & $32(28.6)$ & $32(28.6)$ & $48(42.8)$ \\
$\begin{array}{l}\text { Mm+500 } \mu \mathrm{M} \\
\text { melatonin }\end{array}$ & 108 & $31(28.7)$ & $35(32.4)$ & $42(38.9)$ \\
$\begin{array}{l}\text { Mm+1000 } \mu \mathrm{M} \\
\text { melatonin }\end{array}$ & 120 & $42(35.0)$ & $39(32.5)$ & $39(32.5)$ \\
\hline
\end{tabular}

Chi-square analysis, $\mathrm{p}>0.05$ 
Table 3. Effect of supplementation of melatonin in media for IVM on nuclear maturation of buffalo oocytes after 24 hours of in vitro maturation.

\begin{tabular}{lccccc}
\hline Treatments & No. of & \multicolumn{3}{c}{$n(\%)$} \\
\cline { 3 - 6 } & Oocytes & GV & GVBD & M1 & M2 \\
\hline Maturation media (MM) & 39 & $2(5.1)$ & $5(12.8)$ & $12(30.8)$ & $20(51.3)$ \\
$\mathrm{MM}+250 \mu \mathrm{M}$ melatonin & 33 & & $2(6.1)$ & $8(24.2)$ & $23(69.7)$ \\
$\mathrm{MM}+500 \mu \mathrm{M}$ melatonin & 33 & $1(3.0)$ & $3(9.1)$ & $8(24.2)$ & $21(63.7)$ \\
$\mathrm{MM}+1000 \mu \mathrm{M}$ melatonin & 32 & & $2(6.3)$ & $9(28.1)$ & $21(65.6)$ \\
\hline
\end{tabular}

Chi-square analysis, $\mathrm{p}>0.05$

Table 4. Effect of supplementation of melatonin in media for IVM on in vitro fertilization of buffalo oocytes after 18 hours of insemination.

\begin{tabular}{|c|c|c|c|c|c|c|c|}
\hline \multirow[t]{2}{*}{ Treatments } & \multicolumn{7}{|c|}{ No. of ocytes } \\
\hline & Inseminated & Fertilized & With $2 P N$ & Penetrated & Polyspermic & Not fertilized & Not identified \\
\hline Maturation media (MM) & 43 & $12(27.9)^{b}$ & $11(25.6)$ & $1(2.3)$ & & $30(69.8)$ & $1(2.3)$ \\
\hline $\mathrm{MM}+250 \mu \mathrm{M}$ melatonin & 39 & $18(46.2)^{\mathrm{a}}$ & $18(46.2)$ & & & $15(38.5)$ & $6(15.4)$ \\
\hline $\mathrm{MM}+500 \mu \mathrm{M}$ melatonin & 39 & $17(43.6)^{b}$ & $17(43.6)$ & & & $20(51.3)$ & $4(10.3)$ \\
\hline $\mathrm{MM}+1000 \mu \mathrm{M}$ melatonin & 39 & $17(43.6)^{b}$ & $9(23.1)$ & $4(10.3)$ & $4(10.3)$ & $22(56.4)$ & $6(15.4)$ \\
\hline
\end{tabular}

MM: Maturation media; PN: Pro-nucleus; Chi-square analysis, $\mathrm{p}<0.05$

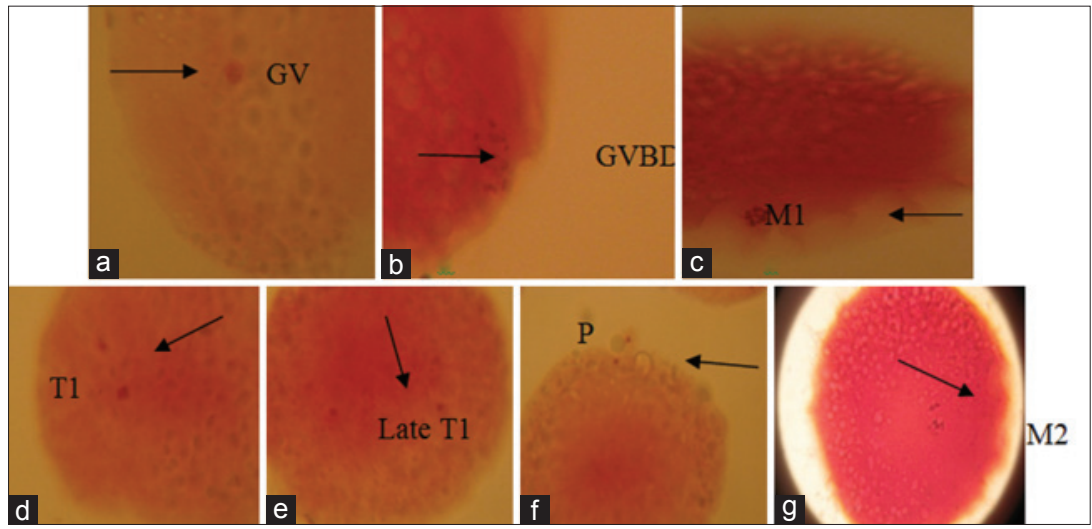

Fig. 3. Different stages of nuclear maturation after 24 hours of IVM. (a) Germinal vesicle (GV), showing nucleolus. (b) Germinal vesicle breakdown (GVBD), showing condensation of chromosomes. (c) Metaphase I (MI), showing chromosomes at meiotic plate without any polar body. (d) Telophase (T1) stage. (e) Late Telophase (T1). (f) Metaphase 2 (M2), stage showing extrusion of first polar body. (g) Metaphase 2. (400x by phase contrast microscopy).

The overall percentage of fertilized oocytes in control and in the media supplemented with $250 \mu \mathrm{M}, 500 \mu \mathrm{M}$ and $1000 \mu \mathrm{M}$ were $27.90 \%, 46.15 \%, 43.58 \%$ and $43.58 \%$ respectively. The percentage of fertilized oocytes in the media supplemented with $500 \mu \mathrm{M}$ and $1000 \mu \mathrm{M}$ melatonin did not differ significantly from the control (MM+BSA). However, percentage of fertilized oocytes was higher $(\mathrm{P}<0.05)$ when the oocytes were matured in media supplemented with $250 \mu \mathrm{M}$ melatonin compared to control.

\section{Discussion}

Maturation involves important events which an oocyte needs to complete for successful fertilization and early embryogenesis. Appropriate maturation is the basis for implantation, initiation of pregnancy, and fetal development (Brevini and Gandolfi, 2001; Sirard et al., 2006). Generally, maturation involves accumulation of mRNA, proteins, substrates, and nutrients that are required to achieve oocyte's developmental competence that fosters embryonic developmental competence (Brevini and Gandolfi, 2001; Krisher, 2004; Sirard et al., 2006).

The oocytes are more exposed to light, air and chemicals during in vitro handling that is responsible for generation of reactive oxygen species (ROS). Buffalo oocytes were found much sensitive to stress caused by 


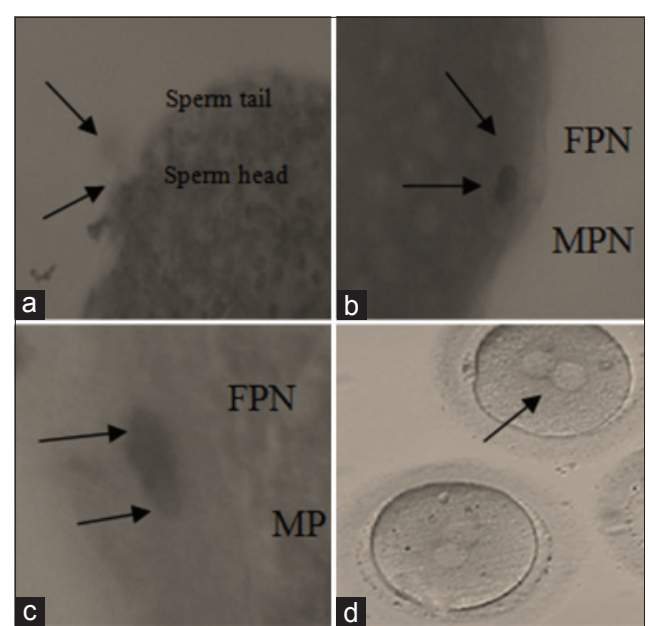

Fig. 4. Different stages of in vitro fertilization (IVF) of buffalo oocytes after 18 hours of insemination. (a) Penetrated oocytes showing sperm head and tail. (b\&c) Fertilized oocytes showing fused male (MPN) and female pro-nucleus (FPN). (d) Fertilized oocyte with two nuclei. (400x by phase contrast microscopy).

reactive oxygen species during culturing in laboratory (Boni et al., 1992). The oocyte developmental competence was reported to be improved by increasing the antioxidant capacity of oocytes during IVM, as the high lipid content makes buffalo oocytes/embryos sensitive to oxidative damages (Boni et al., 1992).

Melatonin has the ability to scavenge oxygen radical, and is effective in reducing apoptosis in different cell types (Allegra et al., 2003; Juknat et al., 2005). Melatonin reduces oxidative stress of ovarian follicles and helps in protection of oocytes from free radical damage (Takasaki et al., 2003; Tamura et al., 2008). Melatonin receptors have been reported on cumulus cells and when supplemented in maturation media, it reduced apoptosis of cumulus cells in mouse $(\mathrm{Na}$ et al., 2005). Further, improvement in maturation and cleavage rates with the supplementation of melatonin in IVM and IVF medium was reported in mice ( $\mathrm{Na}$ et al., 2005), bovine (Dimitriadis et al., 2005) and humans (Parka et al., 2006). Similarly, positive effect of melatonin was reported during in vitro embryo development in mouse (Ishizuka et al., 2000), pig (Rodriguez et al., 2007, Kang et al., 2009, Shi et al., 2009) and buffalo (Manjunatha et al., 2009).

The overall recovery rate of oocytes in our study was lower as the study was conducted in the low breeding season that affects the overall production of progesterone and estradiol required for follicular growth and development. In present study, the percentage of fully expanded COCs decreased progressively with increasing melatonin concentration but difference in the degree of cumulus expansion between different concentrations of melatonin and control was not significant $(\mathrm{P}>0.05)$. The dose dependent effect of melatonin on cumulus cells expansion has previously been reported in mouse (Adriaens et al., 2006).

The rate of nuclear maturation did not differ significantly with melatonin supplementation $(250 \mu \mathrm{M}, 500 \mu \mathrm{M}$ and $1000 \mu \mathrm{M})$ of IVM and control $(0 \mu \mathrm{M})$ in the present study $(\mathrm{P}>0.05)$ as reported earlier that higher concentrations of melatonin mighthave negativeeffect onsurvival of follicles leading to lower rates of maturation (Adriaens et al., 2006). In contrast to our study, useful effects of melatonin have been reported during porcine IVM (Kang et al., 2009). Similarly, increase in the maturation rate and transformable embryo yield was reported earlier in buffalo when melatonin was supplemented in IVM media (Manjunatha et al., 2009). Furthermore, as the melatonin receptors are present in bovine cumulus cells and its lower concentrations ( $0.1 \mathrm{pM}$ to $1000 \mathrm{nM})$ may positively affect cytoplasmic and nuclear maturation (Raey et al., 2011), however, it was not observed in present study.

In present study, the IVF rate of oocytes was independent of maturation rate and was significantly improved in the group treated with $250 \mu \mathrm{M}$ of melatonin. The beneficial effects of melatonin on in vitro embryo development have already been reported in mouse (Gao et al., 2012) and in buffalo (Zhang et al., 1995). However, in bovine, melatonin supplementation of IVM media did not improve the cleavage and blastocyst rates (Tsantarliotou et al., 2007). The supplementation of melatonin in IVM and IVF medium simultaneously, improved maturation and cleavage rates in mice ( $\mathrm{Na}$ et al., 2005), bovine (Dimitriadis et al., 2005) and humans (Parka et al., 2006). This study showed that increasing melatonin concentrations beyond $250 \mu \mathrm{M}$ does not have any significant effect on maturation rates of buffalo oocytes. Melatonin at higher concentrations may be toxic and may result in cell injury and lower blastocyst rates due to its toxicity (Rodriguez et al., 2007). So, it is concluded that addition of melatonin at $250 \mu \mathrm{M}$ improved the fertilization rates of buffalo oocytes, although it did not show improvement IVM rate of buffalo oocytes.

\section{References}

Adriaens, I., Jacquet, P., Cortvrindt, R., Janssen, K. and Smitz, J. 2006. Melatonin have dose-dependent effects on mouse folliculogenesis, oocyte maturation capacity and steroidogenesis. Toxicology 228, 333-343.

Agarwal, A., Tamer, S., Mohammed, A.B., Jashoman, B. and Juan, B.A. 2006. Oxidative stressing assisted reproductive techniques. Fertil. Steril. 86, 503-512.

Allegra, M., Reiter, R.J., Tan, D.X., Gentile, C., Tesoriere, L. and Livrea, M.A. 2003. The chemistry of melatonin's interaction with reactive species. J. Pineal Res. 34, 1-10. 
Boni, R., Santella, L., Dale, B., Roviello, S., Palo, D.R. and Barbieri, V. 1992. An ultrastructural study of maturation in buffalo oocytes. Acta Med. Vet. 38, 153-161.

Brevini, T.A. and Gandolfi, F. 2001. The maternal legacy to the embryo cytoplasmic components and their effects on early development. Theriogenology $55,1255-1276$.

Dimitriadis, I., Paapanikolau, T., Vainas, E., Amiridis, G.S., Valasi, I., Samrtzi, F. and Rekkas, C.A. 2005. Effects of melatonin on in vitro maturation of bovine oocytes. Annual Conference of the European Society for Domestic Animal Reproduction (ESDAR) Murcia, Spain, pp: 397.

Gao, C., Han, H.B., Tian, X.Z., Tan, D.X. and Wang, L. 2012. Melatonin promotes embryonic development and reduces reactive oxygen species in vitrified mouse 2-cell embryos. J. Pineal Res. 52, 305-311.

Hafez, B. and Hafez, E.S.E. 2000.Appendix IV:Technique for Determining Spermatozoal Concentration Using a Hemacytometer, in Reproduction in Farm Animals, $7^{\text {th }}$ Edition, Lippincott Williams \& Wilkins, Baltimore, Maryland, USA. doi: 10.1002/9781119265306.app4.

Hewitt, D.A., Watson, P.E. and England, G.C.W. 1998. Nuclear staining and culture requirements for in vitro maturation of domestic bitch oocytes. Theriogenology 49, 1083-1101.

Ishizuka, B., Kuribayashi, Y., Murai, K., Amemiya, A. and Itoh, M.T. 2000. The effect of melatonin on in vitro fertilization and embryo development in mice. J. Pineal Res. 28, 48-51.

Jamil, H. 2007. Studies on in vitro maturation, sperm preparation and fertilization of Nili-Ravi buffalo follicular oocytes. $\mathrm{PhD}$ Thesis, University of Agriculture, Faisalabad.

Jamil, H., Samad, H.A., Rehman, N.U., Qureshi, Z.I. and Lodhi, L.A. 2007. In vitro Maturation and Fertilization of Riverine Buffalo Follicular Oocytes in Media Supplemented with Oestrus Buffalo Serum and Hormones. Acta Vet. Brno. 76, 399-404.

Juknat, A.A., Mendez, M.V., Quaglino, A., Fameli, C.I., Mena, M. and Kotler, M.L. 2005. Melatonin prevents hydrogen peroxide-induced Bax expression in cultured rat astrocytes. J. Pineal Res. 38, 84-92.

Kang, J.T., Koo, O.J., Kwon, H.J., Park, H.J., Jang, G., Kang, S.K. and Lee, S.C. 2009. Effects of melatonin on in vitro maturation of porcine oocyte and expression of melatonin receptor RNA in cumulus and granulosa cells. J. Pineal Res. 46, 22-28.

Krisher, R.L. 2004. The effect of oocyte quality on development. J. Anim. Sci. 82, 14-23.

Manjunatha, B.M., Devaraj, M., Gupta, P.S.P., Ravindra, J.P. and Nandi, S. 2009. Effect of taurine and melatonin in the culture medium on buffalo in vitro embryo development. Reprod. Domest. Anim. 44, 12-16.
Mehmood, A. 2007. Development of homologus in vitro fertilization test to predict fertility of buffalo semen. PhD Thesis University of arid agriculture, Rawalpindi, pp: 43.

Na, K., Kim, J., Lee, J., Yoon, T., Cha, K. and Lee, D. 2005. Effect of melatoninon the maturation of mouse GV oocytes and apoptosis of cumulus cells in vitro. Fertil. Steril. 84, 103.

Nandi, S., Raghu, H.M., Ravindranatha, B.M. and Chauhan, M.S. 2002. Production of buffalo (Bubalusbubalis) embryos in vitro: Premises and promises. Reprod. Domest. Anim. 37, 65.

Palta, P., Banzai, N., Prakash, B.S., Manik, R.S. and Madan, M.L. 1998. Endocrinological observation of atresia in individual buffalo ovarian follicles. Indian J. Anim. Sci. 68, 444-447.

Parka, E., Leea, D., Choa, J., Hana, J., Chaa, K. and Yoona, T. 2006. Addition of melatonin in in vitro maturation (IVM) medium increases maturation and fertilization of immature human oocytes. Fertil. Steril. 8, 168.

Raey, E.M., Geshi, M., Somfai, T., Kaneda, M., Hirako, M., Ghaffar, A.A.E., Sosa, G.A., Roos, E.M.E. and Nagai, T. 2011. Evidence of melatonin synthesis in the cumulus oocyte complexes and its role in enhancing oocyte maturation in vitro in cattle. Mol. Reprod. Dev. 78, 250-262.

Rodriguez, O.N., Kim, I.J., Wang, H., Kaya, A. and Memilli, E. 2007. Melatonin increases cleavage rate of porcine pre implantation embryos in vitro. J. Pineal Res. 43, 283-288.

Shi, J.M., Tian, X.Z., Zhou, G.B., Wang, L., Gao, C., Zhu, S.E., Zeng, S.M., Tian, J.H. and Liu, G.S. 2009. Melatonin exists in porcine follicular fluid and improves in vitro maturation and parthenogenetic development of porcine oocytes. J. Pineal Res. 47, 318-323.

Singhal, S., Prasad, S., Singh, B., Prasad, J.K. and Gupta, H.P. 2009. Effect of including growth factors and antioxidants in maturation medium used for in vitro culture of buffalo oocytes recovered in vivo. Anim. Reprod. Sci. 113, 44-50.

Sirard, M.A., Richard, F., Blondin, P. and Robert, C. 2006. Contribution of the oocyte to embryo quality. Theriogenology 65, 126-136.

Sirotkin, A.V. and Schaeffer, H.J. 1997. Direct regulation of mammalian reproductive organs by serotonin and melatonin. J. Endocrinol. 154, 1-5.

Takasaki, A., Nakamura, Y., Tamura, H., Shimamura, K. and Morioka, H. 2003. Melatonin as a new drug for improving oocytes quality. Reprod. Med. Biol. 2, 139-144.

Tamura, H., Takasaki, A., Miwa, I., Taniguchi, K., Maekawa, R., Asada, H., Taketani, T., Matsuoka, A., Yamagata, Y., Shimamura, K., Morioka, H., Ishikawa, H., Reiter, R.J. and Sugino, N. 2008. 
Oxidative stress impairs oocyte quality and melatonin protects oocytes from free radical damage and improves fertilization rate. J. Pineal Res. 44, 280-287.

Tsantarliotou, M.P., Altanasio, L., Rosa, A.D., Boccia, L., Pellerano, G. and Gasparrini, B. 2007. The effect of melatonin on bovine in vitro embryo development. Ital. J. Anim. Sci. 6, 488-489.

Wang, X., Falcone, T., Attaran, M., Goldberg, J.M., Agarwal, A. and Sharma, R.K. 2002. Vitamin C and vitamin E supplementation reduce oxidative stressinduced embryo toxicity and improve the blastocyst development rate. Fertil. Steril. 78(6), 1272-1277.

Zhang, L., Jiang, S., Wozniak, P.J., Yang, X. and Godke, R.A. 1995. Cumulus cell function during bovine oocytes maturation, fertilization and embryo development in vitro. Mol. Reprod. Dev. 40, 338-344.

Zicarelli, L. 1994. Management under different environmental condition. Buffalo J. 2, 17-38. 